\title{
Barbara J. Wolfson, MD, FACR (March 2, 1946 - Dec. 15, 2015)
}

\author{
Eric N. Faerber ${ }^{1} \cdot$ Frank R. Pianki $^{2}$ • Gregory J. Toussaint ${ }^{3} \cdot$ Laurence P. Kleiner $^{4}$. \\ Emily Browning ${ }^{2}$ Elizabeth H. Ey ${ }^{2}$ (D)
}

Received: 1 February 2016/Accepted: 4 February 2016/Published online: 3 March 2016

(C) Springer-Verlag Berlin Heidelberg 2016

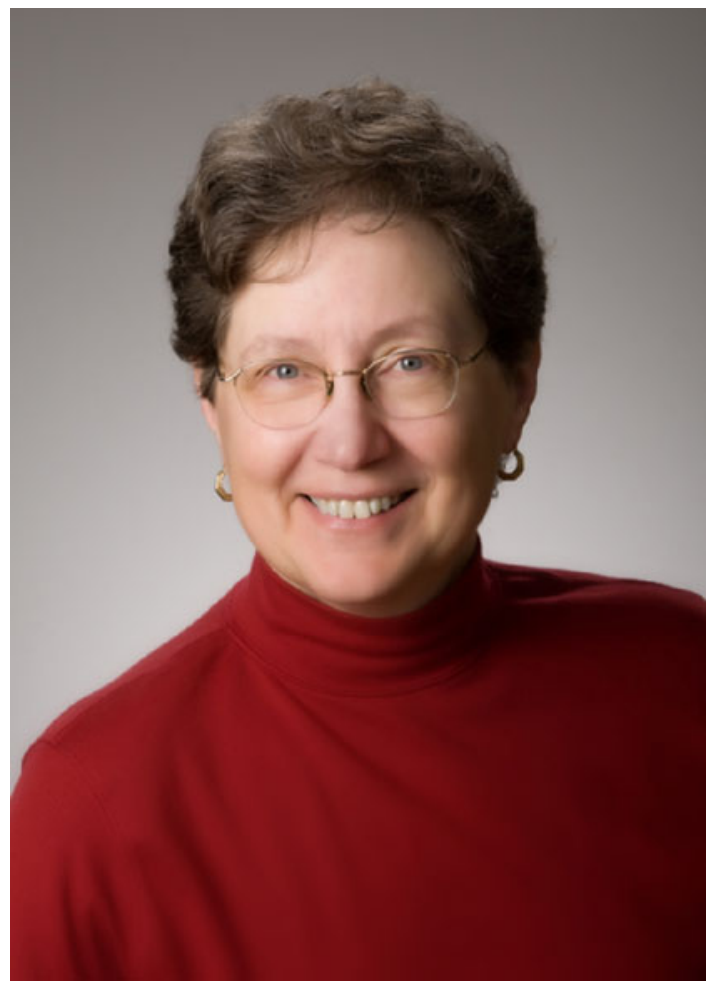

Elizabeth H. Ey

beth@dpi-pedrad.com

1 Department of Radiology, St. Christopher Hospital for Children, Philadelphia, PA, USA

2 Department of Medical Imaging, Dayton Children's Hospital, One Children's Plaza, Dayton, OH 45404, USA

3 Department of Pediatrics, Wright State University Boonshoft School of Medicine, Dayton, OH, USA

4 Department of Neurosurgery, Dayton Children's Hospital, Dayton, OH, USA
Barbara Jane Wolfson, a beloved and much respected pediatric radiologist, passed away on Dec. 15, 2015, after a long and courageous battle with cancer.

She was born March 2, 1946, in Buffalo, NY. Her childhood was deeply influenced by her mother, Dr. Helen Toskov, a pathologist, and her father, Dr. Irving Wolfson, a proctologist. It was from these talented and compassionate physicians that Barbara learned first-hand the challenges and rewards of being a great physician. Barbara obtained a Bachelor of Arts from Barnard College in New York. She was then employed as a secretary for a New York literary agency, where she encountered many celebrities. These encounters would serve her well throughout her career because she would later regale her radiologic colleagues with numerous vignettes from this time. This was followed by pre-med years at Columbia University, New York, and medical school education and radiology residency at New York Hospital, which she finished in 1978.

She completed a fellowship in pediatric radiology at St. Christopher's Hospital for Children in Philadelphia, under the supervision of legendary pediatric radiologist Dr. Marie Capitanio, who became her lifelong mentor. In 1979, Barbara accepted an attending position at that hospital, where she remained until 2004. Barbara soon gained the respect and admiration of all who worked with her. She worked tirelessly for the hospital, clinicians, patients and their parents. She was a member of numerous committees, where her input was highly valued. She also served as president of the medical staff for St. Christopher's.

Barbara very much enjoyed and excelled at teaching. She taught a wide variety of people, including medical students, pediatric and radiology residents, and clinicians in all different departments. Her excellent lectures and teaching points are remembered to this day. She had very high expectations of students and residents and was uncompromising in her teaching approach. She was the recipient of the Victor C. Vaughn Teaching Award from St. Christopher's Hospital for Children in Philadelphia in recognition of her skills. Not to mention, her 
encyclopedic recall of patient names and diagnoses was unsurpassed.

Her major interest was in ultrasound, and she served as chief of the ultrasound section for 19 years at St. Christopher's. She rose to the rank of professor of radiology at Drexel University College of Medicine. She served on numerous committees, regionally and nationally, including the Philadelphia Roentgen Ray Society, Pennsylvania Radiological Society and the Society for Pediatric Radiology. In 2004, Barbara left St. Christopher's to join the radiologists and staff at Dayton Children's Hospital in Ohio.

In Dayton, Barbara continued to pursue her interest in medical education and ultrasonography. She became a clinical professor at Wright State University Boonshoft School of Medicine and began a lecture series for first-year medical students on correlative anatomy and medical imaging that continues today. Her incredible clinical knowledge and talent for teaching were so strong that many experienced physicians changed the way they had read images as a result of her teaching.

Teaching was her passion and where she truly excelled. Her ability to communicate difficult concepts in a clear and concise manner was a true gift. Barbara's mantras for interpreting studies are still quoted by current residents, having been passed to them over the years from those she originally taught. Barbara also served on several hospital committees and projects in Dayton. She was always interested in learning and adapting to the newest technologies. She was thrilled with the use of 3-D and multiplanar imaging, teleradiology, teleconferencing, as well as PACS. As a former secretary, Barbara appreciated voice-recognition technology but would become frustrated by misrecognition. We all remember with a smile the times we reminded Barbara that voice recognition did not improve by shouting at the system. Barbara also enjoyed being a shareholder and employee of Dayton Pediatric Imaging Inc., where she appreciated the responsibilities and autonomy of private practice. In the community of Dayton, she actively supported the arts and local philanthropies.

Barbara was an extremely warm and kind person, displaying great interest in all those with whom she came in contact. She was forthright and had an amazing sense of humor. Barbara brought a positive energy to the department that will be missed by her colleagues, the patients and their families. Her bedside manner was incredibly unique: she always introduced herself to patients and their family with a smile and a handshake, no matter what the child's age. She would often start her workday by making rounds of the department and saying hello to the technologists and other staff.

Throughout her life, Barbara had a wide range of interests and very much enjoyed theater and music. She loved visiting the Shaw Festival in Niagara on the Lake with her family. Colleagues remember fondly the occasions when she would burst into song, with great recall of the lyrics of many musicals, joined occasionally by one or two others in the reading room! She also enjoyed a variety of sports and was an avid skier. Skiing was a sport that brought her family together and allowed everyone to enjoy the outdoors. She became a great fan of biking on the many Rails to Trails in Ohio and was also fond of biking indoors while cheering on her beloved U.S. team in the Tour de France.

Ultimately, her greatest interest was her family. She was entirely devoted to her husband, Jonathan Kleinman, PhD, daughter Molly, son-in-law Piet, and sons Nathan and Max. She was extremely proud of all their accomplishments. She was also the very proud grandmother of Niels and Renske.

Barbara Jane Wolfson will always be fondly remembered by her many friends and colleagues. To quote her husband, Jon, "Barb was always one who made the most of each day and she cherished her relationships with all the people in her life." Her passing leaves an emotional void in all who knew her. 